\title{
"Once a junkie, always a junkie": a narrative analysis of cinematic representations of the attribution of criminality and deviancy to heroin users
}

\author{
Chris Allen 1,* and Anna-Maria Alberici ${ }^{2}$ \\ 1 University of Birmingham; c.allen.2@bham.ac.uk \\ 2 Independent researcher; tba \\ * Correspondence: c.allen.2@bham.ac.uk; Tel.: +44-(0)7940-537-691
}

\begin{abstract}
This article responds to an identified and significant gap in the existing scholarly canon to consider the extent to which cinematic representations construct heroin users - the 'junkie' - as a criminalised 'Other' which confer legitimacy on the notion that such are criminogenic and deviant. Positioned within the disciplinary bounds of cultural criminology, this article focuses on five films - Sid and Nancy (1986); The Basketball Diaries (1995); Trainspotting (1996); Requiem for a Dream (2000); and, T2 Trainspotting (2017). Drawing together Hall's (1997) theories of representation and Hjelm's (2014) theories of social constructionism, the findings from a narrative analysis of each of the films - individually and comparatively - explores the following themes, junkies: as criminogenic; as dangerous underclass; as embodying decay and depravity; and in relation to female junkies, as junkie whores. In doing so, this article elucidates new thinking and ideas about cinematic representations of junkies and how this shapes and influences social norms and mores.
\end{abstract}

Keywords: heroin users; junkies; cinematic representations; social constructionism; cultural criminology

\section{Introduction}

Since the genesis of cinema, narratives and plotlines about drugs, users, addicts, dealers and their subsequent criminalisation have been a mainstay of the film industry (Boyd, 2008). Simultaneous to this has been the development of abstinence-based policies around drug consumption, both of which have had interesting intersections and crossovers throughout their respective histories. Take for instance silent films such as The Chinese Opium Den. Released in 1894, the film showed explicit examples of drugs, drug usage, drug addicts and their alleged criminality. More importantly for Boyd (2008), the film's racialisation of drug users not only began the process of associating specific drug types with specific groups of people - something which indeed continues to the present day - but so too did it infer that wider society was threatened by the spectre of drugs and those that use them. While Hickmans (2009) argues that society has been largely repugnant of drug users, there has been a relentless process of culturally envisioning them. Contemporary films continue to produce equally problematic representations of drug use and users. As McKenna (2012) notes, such representations continue to perpetuate both the stigmatisation of drugs and drug users but so too reproduce the often inaccurate assumptions and stereotypes that are attributed to them. In reiterating the very real intersection between culture and society identified by Boyd (2008) previously, McKenna (2012) adds that these representations, constructions and inaccuracies far too often mirror the narratives of different governments and politicians to the extent that when conjoined contribute towards an 'authoritative discourse' that not only reinforces the perceived threat being posed to society by drugs and drug users but so too confers legitimacy on advocating ever more punitive measures. 
For Taylor (2008), there is little doubt that these cultural representations and narratives contribute towards the legitimisation of policies and approaches that seek to moralise and demonise drugs and drug users. Given that contemporary representations and constructions of drug users - and drug addicts in particular - in popular culture appear to threaten progression (Lalander, 2003) the result is a hegemonic understanding and conception of of drug use, drug users and drug addiction; one that is intrinsically linked to crime, immorality and deviance (Carnwath and Smith, 2002). While this can be seen with all drugs, Carnwath and Smith (2002) note the link between drugs and criminality is especially profound as regards opiate consumption. As they also duly note, it is also the linkage that has the longest history and greatest pedigree. In this respect, heroin holds the status of the ultimate 'criminogenic drug'. By this, they mean that even in the earliest cultural representations, the link between heroin, its use and its users with crime, criminality and deviance was unduly accentuated. Consequently, heroin and heroin users - the latter commonly referred to as 'junkies', a term that is also used from hereon in to refer to heroin users - have always been 'Othered' and demonised in popular cultural products especially filmic representations (Carnwath and Smith, 2002). While so, few studies to date have sought to explore this: the representation of heroin as a criminogenic drug and of junkies in contemporary cinematic representations.

This article responds to an identified and significant gap in the existing scholarly canon to consider the extent to which cinematic representations construct heroin users - the 'junkie' - as a criminalised 'Other' which confer legitimacy to the notion that such are criminogenic and deviant. Positioning itself within the field of cultural criminology, this article seeks to build on existing knowledge while also contributing new thinking and ideas about the interlinkage between drugs and drug use with crime and deviancy. To do so, this article begins by setting out its analytical framework, one that draws together and explains Hall's (1997) theories relating to representation and Hjelm's (2014) theories relating to social constructionism in conjunction with theories and models relevant to the discipline of criminology and including Becker (1963) and Ferrell (1998) among others. Having also set out the methodological approach, some context will be provided in the form of a brief exposition of the history of heroin and junkies as social problems and criminalised 'Others'. From here, the findings from narrative analyses of five films will be considered. These films are: Sid and Nancy (1986); The Basketball Diaries (1995); Trainspotting (1996); Requiem for a Dream (2000); and, T2 Trainspotting (2017). Structured around narrative themes the findings explore junkies as: criminogenic; dangerous underclass; embodying decay and depravity; and in terms of female junkies, as junkie whores. In conclusion, this article seeks to elucidate any new knowledge and thinking to have emerged from the study.

\section{Analytical Framework}

Cultural criminology emerged out of the work of Ferrell and Sanders (1995) and the interest shown towards popular cultural constructions of crime, criminals and crime control. Of particular importance has been the symbolic representations deployed in popular cultural constructions and their potential to shape and inform meaning and identity (Ferrell, 1998). Cultural criminologists therefore - like their cultural studies counterparts - place a significant emphasis on representation, image, and style among others. This is important because as Ferrell (1998) explains, cultural criminology affords a lens through which researchers can undertake "a journey into the spectacle and carnival of crime, a walk down an infinite hall of mirrors where images created and consumed by criminals, criminal subcultures, control agents, media institutions, and audiences bounce endlessly one off the other". Despite the language, such investigations are not fanciful. As Kane (1998) puts it, they allow the interconnections that exist between cultural constructions and the discourses of state institutions, governmental actors and crime enforcement agencies to be explored and subsequently understood. The approach preferred here fits with Ferrell's (1998) notion of the relevance and importance of cultural criminology in enabling a better understand of the role and meanings attributed to the 'symbolic' in popular culture. This is important because popular cultural constructions not only relate to more widely held social and political constructions but so too have 
the capacity to shape and influence them. Cultural criminology also responds to Becker's (1963) demand that criminologists necessarily consider 'all the people'.

Some explanation is required however as regards the theoretical understandings preferred here. The first of these relates to cultural studies and Hall's (1997) theories of representation whereby meaning is seen to be constructed as opposed being naturally inherent. Consequently, it is the process of construction that attributes meaning. For him, the best way to understand this is through notions of 'representation', something he defines as the way in which societies and voices within them deploy language as a means of saying something meaningful (Hall 1997). Representation therefore is concerned with meaning that is given and subsequently made known. For Hall, this is threefold. The first reflects meaning as it is seen to exist in the world. Consequently, reflective representations have the potential to be fair and accurate. The second is intentional whereby representations convey meaning intended by the producer or constructor. Intentional representations may neither be true nor correct if that what was intended. Third is constructionist where meaning is conceived and put forward through the use of signs and symbols that in turn give meaning. While Hall (1997) is keen to stress that constructionist representations do not deny the existence of the material or 'real', what is important is that the meaning conveyed does not necessarily reflect the material or 'real' because it is constructed and produced. Constructionist representations therefore have the potential to fix meaning and understanding to specific objects and things as also communities and individuals.

Hall's theories of representation therefore have a clear resonance with those relating to social constructionism. For the purpose of this article, Hjelm's (2014) definition is preferred: "social constructionism argues that the human world is not as simple and obvious as it seems and that people, you and I, take actively part in producing and reproducing - constructing - it..." (Hjelm [2] 2014). For him, social constructionism has four functions. First, it ontologically functions to offer a view of what the world is like as also what it consists of. Second, it is epistemological in offering a view of how meaning is produced. Third, social constructionism is critical in that it makes possible thinking and communicating about the world differently. And fourth, it is methodological in that helps study processes and impacts in the social world. Social constructionism therefore shapes and informs both the analytical and theoretical framework adopted here, each of which are drawn upon in varying ways.

As regards constructed representations, Hjelm (2014) notes that neither these nor the meanings given can be accepted without question. This is because they are constructed to narrow down the complexity of social life. For Best (1995), one way of achieving this is through the process of naming whereby 'drug dealer' or 'mass murderer' for instance can be seen to rather more effective in terms of conveying a particular meaning than say 'illegal substance trafficker' or 'social pathologist' (Hjelm 2014). This article is premised on the basis that the criminalisation of junkies is a social construction that effectively functions as a name through which complex meanings are narrowed down. In line with this, this article is also premised on the basis that social constructions of heroin and junkies are analogous with them being social problems. In the field of criminology, Becker (1962) elucidated something similar via labelling theory. As a perspective through which to understand crime and deviance within the context of the social world, he argues that those who are 'labelled' as deviant undergo a significant transformation of status and identity thereby becoming isolated, excluded and categorised negatively: "when a rule is enforced, the person who is supposed to have broken it may be seen as a special kind of person, one who cannot be trusted to live by the rules agreed on by the group, he is regarded as an outsider" (Becker, [1] 1963). 'Deviance' therefore "is not an objective fact, waiting to be catalogued and analysed, but rather a collective process of human creation and subjectivity" (Ferrell, Hayward and Young [37] 2008). As Rock (1973) suggests deviance is "a social construct fashioned by the society in which it is identified" (Rock [19] 1973).

\section{Methodological Framework}

While positioning this article within cultural criminology, the field is not one that is characterised by any preferred methodologies and approaches. As Ferrell (1998) puts it, the field's methodologies comprise a 'melange'. While so, a distinction is normally evident between those who 
prefer ethnographic inspired fieldwork and those who undertake media and textual analyses (Ferrell, 1988). This article prefers the latter on the basis that in the contemporary setting, there is a multiplicity of media through which research can be conducted. Here, the preference relates to film and cinematic representations through which to explore constructions of the junkie and heroin use more broadly. This is because film is a cultural medium that reflects dominant social attitudes at the same time as going some way to shape social perceptions and ideas (Welsh et al, 2011). This is supported by Appel (2008) and Appel and Richter (2007). Interestingly, Surette (2007) suggests that such is even more prominent when fictional representations centre on crime and criminals due to the fact most people have little direct experience of either. For Kappeler (2004), cinematic representations function by providing 'convenient mortar' in that they provide the knowledge that people have about unfamiliar issues. Given that most people have little experience of heroin use and that junkies are typically unknown, it is likely that cinematic representations of both will provide some 'convenient mortar'. Welsh et al (2011) go further. For them, cinematic representations influence judgments about crime and importantly, how those with appropriate power should respond. While this article does not directly posit that representations of junkies in films directly influences and shapes political and policy responses to drug use and users, it does posit that cinematic representations reflect wider social and political attitudes.

Miles and Huberman (1994) suggest that qualitative methods are best suited for investigating media representations. Qualitative methods are also the most appropriate when variations in dialogue and action involving fictional characters, narratives and settings are likely to be evident (Pehlke et al, 2009). The qualitative method preferred here is narrative analysis. Having theoretical resonance with Hall's (1997) notion of constructionist representations, narrative analysis is premised on the basis that it does not approach narratives and the stories that emanate from them as a medium that transmits a set of facts about the world. Like constructionist representations, narrative - in line with Hall's concept of representation - is not primarily concerned with claims to truth (May, 2002). According to Bruner (1986), narratives are constructed as a means through which meaning is given to lived experience. As he goes on, given that narratives can be verbal, textual or visual they help make sense of the more ambiguous and complex aspects of human lives thereby complementing Surette's (2007) observations previously.

Narrative analyses are therefore typically fluid. Some place greater emphasis on the 'content' of the narratives while others on 'meaning' (Polkinghorne, 1995). Some combine the two in varying measures. In this way, narratives can be seen to provide a means through which knowable realities including those that are constructed and produced - can be analysed. While so, this article agrees with Polkinghorne's (1995) observation that narrative analyses need to be reflexive due to the complexity, messiness, inconsistency and ambiguity inherent in stories and narratives. In line with Gehart et al (2007), the approach to narrative analysis preferred here was ongoing; undertaken throughout the research process rather than after data was collected. Incorporating verbal and visual narratives, each of the films were analysed in isolation and as a collective thereby enabling the incorporation of both lesser and meta-narratives (Gerhart et al, 2007). The methodological approach therefore was something of an organic endeavour that sought to identify narratives that provided insight into meaning that was known and importantly, how that meaning was known. I doing so, the approach is appropriate for the field of cultural criminology.

The sampling technique used for this dissertation was non-probabilistic and purposive; identified on the basis of what needed to be known as a means of determining what needed to be identified (Bernard 2002, Lewis \& Sheppard 2006). A fourfold criterion was applied. The first was that a film's main protagonist - or fictional character - had to be a junkie. Second, that in addition to being a junkie the film had to have a narrative about heroin running through its entirety. This ensured that the analyses went beyond individual characters. The third required the film to have had a major release in both the United Kingdom (UK) and United States (US). Finally, the film had to be available to view either on DVD or through streaming services. Using these criteria, a search was undertaken using the IMDb database (IMDb, 2017). Using a series of keywords 'heroin' produced 858 entries, 'heroin user' 10 and 'junkie' 447 . The high number of entries could be seen to be somewhat misleading 
as many of the entries did not necessarily relate to relevant content. For instance, one entry referred to Junkie XL, the chosen name of a composer while another referred to a character nickname in the American television drama series, Trees. Individually viewing each entry not only ensured that the criteria was consistently applied but so too was the number of relevant entries also significantly reduced. For example, films such as Heroin (2017) had to be excluded on the basis that it did not have a major release in the UK. So too The Man With The Golden Arm (1955) which despite being the first film shown in the UK to feature heroin use, was neither contemporarily available to purchase or view. Others such as Midnight Cowboy (1969) were initially included but on viewing were excluded due to the fact that while drug use was a prominent narrative, heroin was neither named nor meaningfully identified. In sum, five films met the sampling criteria: Sid and Nancy (1986); The Basketball Diaries (1995); Trainspotting (1996); Requiem for a Dream (2000); and, T2 Trainspotting (2017).

Each of the films was watched individually during which extensive notes were made. While observations and notes primarily focused on the film's fictional characters that were junkies and of heroin use more widely, notes were also made about the social and cultural context and setting within which the films and ensuing narratives were situated. During individual viewing, no comparative analyses were undertaken. These only took place once all the films had been viewed in order that any emergent meta-narratives could be considered. In undertaking the narrative analyses, it was important to ensure that the analytical framework set out previously was adhered to. As such, narratives were analysed in line with Hall (1997) in order to try and understand not only what meaning was being conveyed but so too how meaning could be seen to be being fixed to certain communities, groups and individuals. One way of doing this was through the lens of what Best (1995) and Hjelm (2014) refer to as the narrowing down on complexity, not least through the use of 'names' and other narrative techniques that seek to attribute or give meaning. Similarly, the construction and representation of heroin users and heroin use as being a social problem was also considered as part of the analysis. This was essential in order to ensure that the narrative analyses undertaken were positioned within the field of cultural criminology..

\section{The 'Junkie' in Historical Context}

The historic nature of opiates have historically transformed from a drug used for its medicinal purposes to one viewed as destructive and dangerous. This transformation was social and political, a crucial distinction to note in trying to understand why heroin and its users became both 'Othered' and criminalised (Carnwath and Smith [6] 2002). The origins of this can be traced back to the Temperance Movement of the nineteenth century. As Bell (1996) argues, key to the success of the Temperance Movement was the perceived threat from increasing hedonism and the ensuing need therefore to focus on frugality as a means of achieving salvation. In seeking to "bring order in the conduct of its adherents" (Weber [119] 1970), opiate-based drugs were seen to be antithetical and thus became seen as the primary causes underpinning a whole raft of different societal problems including poverty, criminality and poor morality (Sulkunen and Warpenius, 2000). With this came greater political interest whereby greater attention was duly paid to the 'scourge of addiction' (Berridge, 1999). Conceived as a medical ailment, addicts were increasingly understood to need to be cleansed as much as they were saved also. In doing so, the problem was seen to shift from being the scourge of the morally weak to those whose personal vulnerabilities compelled social deviance (Berridge, 1999). Importantly, this gave credence to the view that deviance was a personal choice rather than the consequence of structural factors such as poverty or inequality (Springer and Page, 2013).

This was especially pertinent as regards heroin. While opiate users were previously higher class white women, by the start of the twentieth century heroin was a 'problem' increasingly being attributed to poorer, lower class men in the urban spaces: what Courtwright (2001) describes as the 'dope-fiend street criminal'. Concurrent to this was the transformation of opiate users into categories of medical and non-medical users and as regards the latter, the increasing recognition of 'iatrogenic addicts' and 'pleasure seeking addicts'. Codified as problematic but more importantly, socially deviant also (Courtwright, 2001), iatrogenic addicts were increasingly seen to be linked to usage of the newly created diacetylmorphine - or heroin - in 1868. While the new opiate-based drug was seen 
to be a problem of the Chinese, non-white communities and the lower classes, it was also seen to be the choice of the 'criminal underworld' and thereby "alien, dirty and depraved" (Carnwath \& Smith [16] 2002). For Berridge (1999), it was this coupling of associations with class and criminality that was most determinative in shaping social constructions. From the outset then, heroin was deemed to be problematic.

For Lee (2015), this catalysed the construction of heroin user as 'junkie'. Graber and Dunaway (2016) highlight the importance of the media in achieving this. For them, media representations of junkies were routinely deployed as a means of maintaining and reinforcing the political ideologies and policies associated to them that sought to control and criminalise drugs and drug use. Entirely hegemonic, this was evident in "the way in which certain groups exerting social authority and control over subordinate groups by obtaining and moulding consent so that the actions and power held by the higher classes appear legitimate and natural" (Lavoie [912] 2011). Consequently, certain meanings became increasingly attributed and subsequently normalised as regards junkies especially in representations within the news and other popular cultural outputs. As Hickman (2002) put it:

"Everyone knows what a junkie is supposed to look like: hollow cheeks, panda eyes, a haunted expression, wasted, decadent desperate. And yet, narcotic addiction, as a physiological or psychological condition is invisible. It offers no infallibly visible markers of its presence" (Hickman [1475] 2002).

While having a historical grounding, the name 'junkie' emerged from sustained media coverage in the early 1950s of groups of men who lived in New York and were renowned for collecting and selling scraps of metal as a means of acquiring money to sustain their heroin addiction. The name therefore literally meant 'junkman' (Radcliffe and Stevens, 2008 p.1065). The name was also symbolically appropriate given that "within a short amount of time, the locus of addiction had shifted from the office or parlour to addiction and addicts as desolate urban debris" (Courtwright [110] 2001). By the 1953 publication of William Burroughs's popular literary autobiographical account Junky, the name 'junk' had come to mean heroin itself and 'junkie' the "morally degenerate user" (Reinerman and Levine [3] 1997). Consequently, both the name and notion was coined and constructed within the context of the media and popular culture, two settings where it has continued to be coined and used as a means of constructing criminality and deviance (Lee [2] 2015). Similar constructions have been recurrent ever since in both the US and UK.

According to Huggins, media and popular cultural constructions have also unduly focused on junkies bodies as a way of reproducing and constructing ongoing representations of the "threatening junkie..." that reinforced the widely held and historically informed view that heroin users were "...deprived, dirty, injecting dope-fiends" (Huggins [166] 2006). As decaying and filthy, he argues that the body:

"acts as a map for the (perceived) social significance of drug use and addiction, one maps onto the other and back again as the centrality of symbolic and representational form both enhances and is enhanced by the socially marginal location of the addict" (Huggins [166] 2006)

Turner (2003) agrees but adds that notions of filth and decay can also be seen in the undue focus on the urban decay and squalor within which popular cultural representations tend to show junkies inhabiting. Another is the undue emphasis placed on representations which show heroin needle being used to ingest heroin. In these, the body of the junkie is always paramount (Turner [3] 2003). For Turner (2003) these representations seek to reinforce constructed meanings that junkies are not only 'abnormal' but through metaphor and symbol also convey that such only occurs in the context of disorder, danger and threat. In doing so, it becomes easy to promote anti-drug messages and develop ever more punitive legislative and policy responses (Huggins [168] 2006). Such representations are crucial in constructing what a junkies looks like namely, dirty, decaying, depraved and unhealthy (Huggins [173] 2006). Recurrently, media and popular cultural 
300

301

302

303

304

305

306

307

308

309

310

311

312

313

314

315

316

317

318

319

320

321

322

323

324

325

326

327

328

329

330

331

332

333

representations construct junkies as powerless, strange and alien; rarely a face of an "ordinary, living drug user, only a suffering, monstrous, freakish diseased Other" (Fitzgerald [380] 2002).

For Loukides and Fuller (1996), there is a need to recognise how important media and popular cultural representations are in shaping and informing understanding while also giving meaning to the social world, social issues and social problems. They refer to the media and popular culture as functioning with 'ideological agency', whereby constructions and representations that are routinely and repeatedly employed are also typically mythologised. For them, such are embedded within dominant ideologies which propagate myths of "individualism and personal choice, institutional neutrality and the absence of class, gender and racial divisions enforcing personal rather than institutional responsibility for social ills and immoral behaviour" (Loukides and Fuller [167] 1996). Reinerman and Duskin (1999) concur. From their research into drug use, they put forward the belief that the media constructs junkies extremely narrowly, characterised by the "routinisation of caricature..." which actively "...promotes worst case scenarios as the norm and sensationalizes drug use and users in the media" (Reinerman and Levine [49] 1999).

Ferrell, Hayward and Young ([4] 2008) state that this is most evident in representations of junkies in film. While so, investigations show that very few scholarly studies have been undertaken to investigate this. From a cultural criminology point of view, this is problematic as popular cultural constructions relating to all forms of crime provide insights into "collective meaning and collective identity..." not least because "...within it and by way of it, the government claims authority, the consumer considers brands of bread - and the 'criminal', as both person and perception, come alive" (Ferrell, Hayward and Young [2] 2008). Despite the lack of scholarly inquiry into cinematic representations of junkies, Stevenson (1999) observes how "motion pictures serve as incubators and conduits of myth for modern audiences, and a cultural reservoir, which indirectly or directly influences societal perceptions" (Stevenson [11] 1999). As regards junkies this is even more pressing given that until the 1950s, heroin and its use was banned from mainstream cinema screens (Stevenson, 2000). After the demise of 'old Hollywood' cinema, the easing of censorship regulations meant that drugs, drug use and drug addiction began to appear on screens. Maybe surprisingly, Markert (2013) notes that since then heroin has become the most common drug when films seek to represent narratives about addiction. This dissertation therefore not only seeks to contribute knowledge to an identified gap in the scholarly literature but so too consider the most demonised and most 'criminogenic drug' in the form of cinematic representations as a lens through which to try and better understand constructions which seek to inform and give meaning to the social world (Stevenson [12] 2000).

\section{Findings from the Narrative Analysis of Five Cinematic Representations}

\subsection{Heroin Users as Crimonogenic}

Without doubt, each of the films resonated with Carnwath and Smith's (2000) observation that heroin is the most 'criminogenic drug'. In The Basketball Diaries for instance, the main protagonist Jim is shown to progress into criminality on the basis that he was unable to cope financially with the demands of his heroin habit especially once he began to use more and more. This was further reinforced through the words of Jim which are deployed to narrate the story throughout the film. Integral to this is the primary narrative whereby Jim chronicles his descent into crime and criminality. Increasingly deviant - and deviating from what would be seen to be society's norms - the film's overarching narratives are such that they fit with the representation of the drug user in popular culture as defying society's normative morality. These constructions are further given meaning as the film unfolds and the true extent of Jim's criminality and deviance become known. Somewhat ominously, Jim self-references the fact that he engages in "unpure activities" some of which are shown to include auto theft, robbery, purse snatching and hustling all of which are undertaken as a means of securing money to fund his heroin habit. Again reinforcing wider constructions through Jim's own self narrative, he notes that while he "does not like mugging people..." he adds that this is "...now his only way out". In seeking to reinforce Jim's descent into criminality, the film jumps 
from a visual representation of him robbing a victim at knifepoint to participating in prostitution, selling himself in public toilets for cash before hinting at having to engage in sex acts that involved him dressing in women's clothes. Consequently the narrative illustrates the transformation of Jim from being a 'normal' person prior to his dalliance with heroin to one that is codified as not only being criminalised but deviant also.

At the start of Requiem for a Dream, the film's three main protagonists - Harry, Tyrone and Marion - are known to use heroin for recreational purposes. In developing the film's narrative, Harry and Tyrone are seen testing the quality and strength of the heroin with the intention of selling it on the streets in order to build their own "drug empire". Interestingly, the film's narrative implies low morality through developing the narrative in order to show that this is solely for the purpose that the two protagonists can "have as much heroin and money as they like". Unlike Harry and Tyrone, Marion is represented as being a more "creative or spiritual user"; where heroin helps her to feel real and somewhat tragically, more loved by Harry who also happens to be her boyfriend. As with The Basketball Diaries, the film's narrative sets out how despite her heroin use being initially recreational she soon descends into criminal and deviant acts not least prostitution illustrated by scenes of her having sex with her therapist, pimps, and strangers at a sex party in exchange for money and at times, heroin. The underlying cause for her descent is captured in a narrative exchange between Marion and Harry. Having convinced Marion to have sex with her therapist as a means to gain a "score" Marion says:

Marion: "Getting the money's not the problem, Harry"

Harry: "Then what's the problem?"

Marion: "I don't know what I'm going to have to do to get it"

While the friends are not seen stealing or mugging as was the case with Jim previously, Requiem for a Dream's director Darren Aronofsky makes clear that there are criminal undertones to their heroin use. This can be seen in narratives that set out the extreme acts of sexual depravity preferred by Marion, Tyrone's increasing involvement with a drug cartel in order to buy and sell heroin, and Harry's acquisition of large sums of illegal money in order to buy large "scores" of heroin in order to create his drug "empire". As the film's develops, while the group is shown to establish a small drug dealing business so the narrative illustrates how they all become increasingly tolerant to the effects of heroin resulting in them quickly becoming addicted to the drug which supersedes their individual and collective abilities to be able to distribute and subsequently sell.

While the depiction of moral impurity and the ongoing representation of criminality and deviance are recurrent throughout, the film's closing scenes are most telling. Harry is admitted to hospital alongside Tyrone as a result of an infection in his arm. The narrative explains that the infection is a consequence of his repeated use of a dirty hypodermic needle. The association of criminality and heroin is a primary feature of the film's closing narrative. As soon as medics see Harry's infected arm, police officers and the Sheriff are shown to arrive at the hospital to arrest Harry on suspicion of drug charges. At the same time, Tyrone is seen craving heroin as his heroin hit wears off before being arrested along with Harry having been stalked in the hospital waiting room by police. Despite the scene's narrative showing that Tyrone was trying to hide and mask his supposed criminality, the meaning put forward in the narrative is one where the link between heroin use and criminality and deviance is undoubtedly clear. In reiterating the findings from the previous section, police officers are seen laughing and mocking Harry and Tyrone:

"That's the trouble with ya New York dope fiends. Ya got a rotten attitude" (Requiem for a Dream, 2000)

Junkies as criminogenic are also embedded in the main narratives of Danny Boyle's film, Trainspotting. Although critically acclaimed as an empathetic representation, the film's narratives embody many of the same stereotypical themes and meanings as those identified in the films 
402

403

404

405

406

407

408

409

410

411

412

413

414

415

416

417

418

419

420

421

422

423

424

425

426

427

428

429

430

431

432

433

434

435

436

437

438

439

440

441

442

443

444

445

446

447

448

449

450

considered previously. The opening scene shows the main protagonist Mark Renton - who is also the film's narrator - running to escape a shop security guard, chasing him and his fellow junkie friends Spud and Sick Boy. The initial narrative that emerges in the opening credits is one of junkies as being criminal, stealing and hustling as a means of obtaining a 'score'. The main and most stringent theme demonstrated within Boyle's narrative is one that shows the film's junkies as "dole fiddlers, engaging in senseless violence, casual theft, and underage sex" (Stevenson [207] 2000). The film's opening narration is taken straight from Irvine Welsh's critically acclaimed novel of the same name. Popularly referred to as Renton's 'Choose Life' speech, the unfolding narrative speaks about the limbo of heroin addiction and how anything within contemporary culture is different than living a life on the margins of society:

"Choose Life. Choose a job. Choose a career. Choose a family. Choose a fucking big television, choose washing machines, cars, compact disc players and electrical tin openers. Choose good health, low cholesterol, and dental insurance. Choose fixed interest mortgage repayments. Choose a starter home. Choose your friends...... Choose your future. Choose life. But why would I want to do a thing like that? I chose not to choose life. I chose somethin' else. And the reasons? There are no reasons. Who needs reasons when you've got heroin?" (Trainspotting, 1996).

As Renton's narration ends, the film shows the security guard catching up with the group resulting in a violent fight between Sick Boy and the guard. While so, the emphasis on choice and autonomy highlights the ongoing societal belief that junkies make an informed choice about using the drug. In doing so, Welsh and Boyle subsequently ignore the structural and socio-economic disadvantages experienced by users especially those that would have prevalent in 1990s Scotland. The emphasis on choice therefore confers legitimacy.

As with Requiem for a Dream, the narrative associated with the main protagonist in Trainspotting illustrates a slow progress into deeper criminality. In doing so, Renton and his groups of friends plan to sell a large amount of heroin which they have obtained in exchange for cash. Having made the sale, Renton takes off with all the money in order to start a new life leaving his friends behind in Edinburgh. In doing so, the narrative questions Renton's morality; something that is a recurrent and somewhat constant narrative throughout the entirety of the film. What is interesting is that while the film is based around the premise of friendship, the film's narrative is such that it constantly implies that junkies are little more than a connected group of criminal desperados whose lives revolve around heroin in particular the need to secure their next "fix" or "score" (Stevenson [214] 2000).

In line with Ferrell (1998), this along with the overarching narrative and surreal style of Trainspotting is such that the watching public clearly engages in "a journey into the spectacle and carnival of crime, a walk down an infinite hall of mirrors where images created and consumed by criminals, criminal subcultures, control agents, media institutions, and audiences bounce endlessly one off the other" (1998). In this way, despite being perceived to be somewhat more empathetic to junkies, it offers much the same representations about users as those films that might appear somewhat less so. Framed within the theoretical lens of Hall (1997), it is quite clear that irrespective of the perceived positionality of the film - empathetic or otherwise - the process of construction and the meaning subsequently attributed would appear to be much the same. In saying something meaningful about the world, what the narrative analysis shows is that heroin is undoubtedly represented as a criminogenic drug where its users are repeatedly shown to be drawn into criminality and social deviance. While Hall (1997) stresses that representations do not deny the existence of the material or 'real', what emerges from the narratives of the films analysed here is that the 'real' can also be deployed in order to codify and concretise meaning that is rather more constructed and produced. 
The second clear narrative theme was junkies as part of a dangerous underclass, again resonating with historical notions. For Jones (2012), this is particularly important in that it has been a recurrent theme within cinematic representations. This was true of the films analysed here where representations of junkies being an underclass evident in all of the films. From the analysis, this was most prominent in Trainspotting and T2. It is possible that this was because both films were situated within the reasonably contemporary British context and were linked, $T 2$ being a sequel of sorts to Trainspotting. Both films depict a group of socially isolated individuals who are not only from lower socio-economic backgrounds but also participate in criminality and use heroin. In the second scene of Trainspotting - after the Renton scene referred to previously - the narrative introduces one of the main locations preferred in the film, Spud's squalid and filthy flat. To represent this, the flat is seen to have urine soaked carpets that are scattered with various paraphernalia required to administer heroin including used needles, foil and heating equipment. This visual narrative is recurrent throughout the film. In doing so, the repeat use of this within the narrative development of the story is such that it continually reminds and subsequently reaffirms the squalor and filth associated with heroin users and heroin use also. That they are seemingly willing - and maybe even happy - to exist in these conditions suggests that such are normative and attributive of their normativity.

In another scene in which the narrative restates the association of junkies with an underclass, the character of Alison is introduced. While the narrative quickly establishes her as a 'junkie' she also has a six month old child. Shown to be living alongside other members of the friendship group including Renton and Sick Boy - the narrative develops to explain that she seemingly fails to notice let alone care for the child in preference of shooting up with the intention of getting high. To reinforce this, the child is seen crawling around among the squalor and filth within the flat while Alison and the others appear semi-conscious. Shortly after, the narrative develops whereby the viewer sees Alison screaming at the side of her child; the baby not only being dead but also having started to decompose. Harrowing enough, the narrative attributes further meaning to Alison through inferring how she does not seem to know who the father of the child is. Latterly, it is however hinted that the father is Sick Boy. What is important here is that the notion of illegitimacy is a key characteristic of Murray's (1996) understanding of an underclass. Parental abandonment and neglect are other characteristics associated with the notion of an underclass and both of these are narratively conveyed in Trainspotting via the character of Begbie. Having been constantly portrayed as an angry and violent psychopath across the two films, a scene in $T 2$ shows Renton and Begbie walking around a disused railway station late at night when they encounter an old homeless, dishevelled 'wino'. As the narrative develops, so it becomes apparent that the 'wino' is in fact Begbie's father. In the same film, Begbie's relationship with his own son is also shown to be dysfunctional; again, a characteristic of what Murray (1996) states is a recurrent in representations of 'underclass families'.

When Renton says in T2, "Begbie, staggered off, drunkard cackles filling the desolate barn, I noticed that Begbie seemed strangely subdued and uncomfortable, he was turned away from us, it was only then we realised the old wino was Begbie's father" the narrative gives meaning to the notion that the 'underclass' also reproduces depravity and immoral behaviour, both components of a perceived unbreakable cycle of poverty (Murray, 1996). While the notion of an underclass is evident in Trainspotting, it becomes even more prominent in T2. In fact, the two films complement each other in this respect as they provide a means by which to narratively illustrate what might be referred to as career poverty or career criminality. Considering the lives of the characters through narratives that span the twenty year period between the two films, the narratives remain firmly rooted in the context of junkies and heroin use being criminogenic with characters continuing to participate in hustles to obtain money for drugs at the same time as being portrayed as 'lazy' through the implication of a lack of aspiration or drive as regards more normative life goals.

A similar narrative is apparent in the film The Basketball Diaries. Here, Jim is explained through the developing narrative to come from a single parent household in an area of New York where poverty was known to be rife. Jim, who was previously noted as being routinely engaged in criminal activities also aligns himself with wider notions of an underclass. Like the two Trainspotting films, narratives about Jim explain how his descent into criminality and deviance coincided with his turn 
towards living in filth on the streets of New York. This included Jim being shown in many desolate places, the most prominent being the 'Headquarters' which in fact is little more than a basement where all of the new York's 'street junkies' are known to 'hang out'. In the narrative, Jim observes how most of the people here "have been high for four days of 'temporary death', unable to attempt human posture". The scenes featuring the 'Headquarters' are typified - like Spud's flat in Trainspotting - by the intensely squalid conditions: filth, drug paraphernalia, urine, faeces and stained clothing and carpets being the norm.

The function of these visual and narrative forms is as Hjelm (2014) notes, a way of successfully narrowing down the true complexity of social life, in this context junkies and how they live. In line with Best (1995), instead of giving a name by which a particular meaning can be effectively conveyed these narrative and visual devices perform a similar function. They too convey a very particular meaning which as analysed here would seem to be that heroin users and heroin use are both complicit and indeed conducive to notions of an underclass. Without doubt, these would appear to be social constructions that function in line with Hall's (1997) theoretical premise relating to representation in that they not only confer meaning but so too give that same meaning credence and validity. In this respect, heroin use and heroin users are given meaning that they are both intrinsically linked to notions of an underclass.

\subsection{Heroin Users as Embodying Decay and Depravity}

In line with Huggins (2006), narratives about decay and filth regarding the junkie including the junkie's body were evident in each of the films. What was common were narrative and visual depictions of decaying junkies, each routinely showing the shift from what was perceived to be a 'healthy' drug-free body to a somewhat more 'unhealthy' rotting and bruised body that was the result of heroin use and addiction. Narratives associated with the visual decay of junkies also functioned to represent the embodiment of 'Otherness' thereby establishing them as distinct and different from normative society. For Springer and Page (2013), the visualisation of decay and disease in conjunction with urban squalor contributed to narratives about junkies being alien, having evil impulses and having no loyalty or care for others. In doing so, this gives meaning about what junkies not only look like but more importantly also what they are like. This was apparent in Trainspotting where Renton is almost entirely conceived in narratives that depict notions of squalor, filth and decay. Some of Trainspotting's most memorable scenes exemplify this. In one, Renton is seen being sucked into a faeces-filled public toilet while in another he is seen using a dirty needle; the latter, seeing the camera linger on the needle piercing his skin until he loses consciousness. As with Huggins (2006), focusing on the needle can be seen to be a symbolic of wider narratives about how junkies willingly deface their bodies in pursuit of what might be understood to be self-serving pleasure. This is a recurrent narrative in $T 2$ whereby Spud - despite twenty years having elapsed since the first film - is shown to be still living in the same flat. In situating Spud in this way, a narrative is established between the first and second film which conveys the notion that little changes. In reinforcing this, it is interesting that the character says in the second film, "once a junkie, always a junkie". As with those constructions about junkies and heroin having been shown to be somewhat constant across a reasonably significant period of time, so this would appear to be reinforced in cinematic narratives also.

The embodiment of decay and depravity within the bodies of heroin users was also evident in the narratives of Requiem for a Dream, not least where Harry notices that he has an infected vein from the sustained of using it for injecting heroin. Throughout this scene the camera focuses on the minutiae of administering heroin from the use of hypodermic needles to the belt that is used around the arm in order to heighten veins. In a particularly harrowing scene, Harry's arm is shown to be completely black with the surrounding veins seen to be swollen and red from infection and disease. Despite noticing the infection, the narrative explains how Harry continues to use the same arm and infected veins in order to administer heroin into his body. Having done so, he writhes around in pain. Once the high of the heroin wears off, the film's narrative tells of how Harry admits himself to hospital where the infection is immediately recognised as being the result of injecting heroin. To 
further emphasise the visual decay of Harry's arm - and the association of bodily decay with heroin use - the meaning is given greater credence through the dual reinforcement of visual and verbal narrative devices.

\section{Court Doctor: Can you hear me? Can you see me?}

Prison Guard: He says he's got something wrong with his arm.

[the doctor grabs Harry's arm and exposes the wound, causing him to scream in pain]

Court Doctor: I don't think he'll be puttin' any more dope in that arm.

Prison Guard: Smells worse than he do.

The film also confers similar meanings onto junkies through the development of scenes and plotlines where sexual deviancy is prominent. In one, Marion is forced to engage in anal intercourse with an unknown man while being watched and jeered at by a large group of men. During the scene, the camera initially lingers on Marion's semi-conscious face during intercourse before switching to her face once the sex act is over. In the latter, she appears elated because she is given a bag of heroin in exchange. The representation of Marion in this way reinforces the 'dope-fiend' stereotype previously, denoting that users will do anything to obtain the 'demon drug" (Boyd, 2008).

Similar narratives were apparent in The Basketball Diaries where Jim's body is seen to embody disease and decay. Shown as head of his high school basketball team prior to his heroin use, Jim is depicted as a fit teenage athlete. As the film develops however, the narrative informs the viewer about how Jim's addiction spirals out of control. At the same time, visual narratives show how Jim's physical appearance drastically changes: his eyes become shallow and sunken, his skin pale and puckered with scabs, his body thin and bruised. The attention to the detail in relation to Jim's morphing into an addict is a key narrative which, like Requiem for a Dream reinforces wider constructions relating to what it means to be a "junkie". Jim's decent into depravity is also narratively conveyed in scenes involving Jim and his mother. Realising that he has ran out of money to finance his addiction, Jim visits his mother's apartment. Refusing him and his pleas, Jim verbally abuses her during which he blames her for his addiction. Begging her for money, the narrative develops $p$ show Jim sitting on the floor outside of his mother's apartment while she sits on the other side of the door terrified. This juxtaposition reinforces the visualisation of Jim's body as decaying and him as threatening whilst his mother is represented as the epitome of health and reason thereby giving meaning to confer legitimacy to constructions of heroin users.

In Sid and Nancy (1986) the embodiment of depravity is also evident. In one particularly poignant scene, the main protagonist Sid sings a cover of Frank Sinatra's My Way. From a narrative that illustrates the positive response shown to the song, the scene cuts immediately to Sid lying in a filthy stained bed with Nancy, the film's other main junkie character. In doing so, the narrative juxtaposes the public life of Sid with his private life with Nancy as junkies something that was given greater impact by being interspersed by a conversation with the couple who, having just taken hits of heroin, discuss the prospect of a mutual suicide pact. The couple's final scene in which Nancy dies is the final visualisation to the viewer of how far Sid and Nancy have descended into depravity. Maybe going further with the narrative than the other films analysed, Sid and Nancy conveys the ultimate embodiment of decay on heroin users. Although not formally codified in the film's narrative, the film does show Sid and Nancy arguing during a drug fuelled rage where it is hinted that Sid accidently kills Nancy, who then bleeds to death in the apartment. Not only then does Sid and Nancy narrativise the ultimate embodiment of bodily decay in terms of the resultant death of Nancy but so too does the narrative also infer that it was the use of heroin that was also the cause of that ultimate manifestation of decay. Heroin therefore was both causal and consequential.

\subsection{Female Heroin Users as 'Junkie Whores'}

Narratives that construct female heroin users as 'junkie whores' can be seen in three of the films analysed. Trainspotting, Requiem for a Dream and Sid and Nancy all employ narratives where female characters can be seen to 'sell' their bodies for either money to buy heroin or for heroin itself. Such 
narratives are not without precedent as scholarly evidence suggests that constructions about junkie relationships are rarely viewed as 'normal' or 'real' but instead, almost entirely destructive, exploitative and encompassing of varying levels of suffering (Rinke, 2016). The depiction of female junkies as 'whores' is highlighted in what is described as the 'junkie love' mini genre comprising Sid and Nancy and Requiem for a Dream. Both films show how the love between couples quickly unravels into destruction, abuse and even death as a consequence of the introduction of heroin. In both, the narratives seek to depict the couples to be "possessed by a demon drug..." that in turn transforms them into "...monstrous drug-fiends" (Rinke, 2016 p.8). Both films also portray female junkies as immoral beings who stop at nothing to gain their 'fix'. In Requiem for a Dream, Marion is shown to be in a loving relationship with Harry at the start of the film. The narrative however soon shows how the two begin to use heroin to pass time: Marion repeatedly saying "Do you want to waste some time?" throughout the film. That recreational use however soon becomes problematic once Harry and Marion can no longer obtain it and start experiencing withdrawal symptoms.

From here, Marion is shown to have sex with her therapist in an attempt to acquire money for heroin. Once the ensuing drug deal goes wrong however, Marion begins to engage in prostitution to fund her and Harry's habit:

Harry: [about the failed drug score] Some dumbass junkie...

Marion: Did what? Some dumbass junkie did what? You mean, you fucked it up!

Harry: What the fuck is wrong with you?

Marion: You promised me that everything was gonna be okay, remember? I fucked that sleazebag for you, then I put myself through fucking hell for you?

However Marion's relationship with Harry soon deteriorates once they cannot get heroin. Harry exploits Marion's love by giving a desperate Marion the details of a local pimp for whom she can exchange sex for heroin. The film shows Marion engaging in visibly humiliating sexual activities firstly with the pimp, then at a sex party in which she and another woman engage in sexual activities for a watching crowd. The narratives about Marion therefore codify how female junkies are represented in constructions both about women as indeed junkie relationships.

Similar are evident in Sid and Nancy where Nancy is portrayed as being both desperate and immoral. Nancy is introduced to Sid as someone who just wants to meet a guy who can pay for her 'junk'. Nancy before meeting Sid offers sexual favours to other members of the band (The Sex Pistols) in which they all refuse as she is constantly high and in their view, out to take what she can from them. At this point, the narratives about Nancy already appear somewhat misogynistic and problematic. Throughout the film the phrase "never trust a junkie" is also repeatedly directed towards Nancy. Narratives about Nancy therefore concur with scholarly studies for instance those of Boyd when he states that, "representations of junkie women on screen, reproduce the pleasure of the male gaze, with their characters being overly sexualised and one dimensional, women can be viewed as being characterized as sexually aggressive and promiscuous when using heroin" (Boyd, 2008 p.149). Similar narratives are evident in Trainspotting via the character of Alison. As a young junkie mother, she is seen lying in the filth and squalor of Spud's flat along with other members of the group. Sick Boy is seen preparing Alison's arm for injecting heroin, with a belt wrapped around her arm, before inserting a needle into her vein. Beginning to moan, Alison stares into Sick Boy's eyes and says, "that beats any fucking cock in the world".

In all of Requiem for a Dream, Sid and Nancy and Trainspotting, all the female junkies are shown to have larger appetites for both heroin and sex than their male equivalent. This is apparent when their lovers retreat and want to get 'clean'. In each, the female characters are also shown to be resistant and betraying of their partners. This is especially prominent in the narratives of Sid and Nancy when Nancy threatens to 'rat' on Sid if he leaves her. Prostitution too is shown in all three movies as the only way out for the women albeit one that each of the female characters also appears to be wholly willing and even complicit to participating in. Not only does this reinforce the image of the female junkie as 'junkie whore' but so too does it support Hall's (1997) theory that representations have the 
ability to convey particular meanings about certain individuals, groups and communities. As well as being problematized in terms of being heroin users, constructions of female heroin users are further problematized by the added constructed meanings that infer negative attributes in terms of greater sexual desire, greater propensity for heroin, and a greater willingness to betray those who appear to stand in the way of their pursuit of sex or heroin or both. In doing so, representations of female heroin users further elucidate the construction of heroin as a criminogenic drug that is indeterminably connected to criminality and deviance.

\section{Conclusion}

Positioned within the field of cultural criminology, this article sought to consider the importance of popular cultural representations - in particular cinematic representations - in constructing and representing heroin and its users - junkies - as social problems. Through the lens of social constructionism in accordance with Hjelm (2014), this dissertation looked at the construction of heroin users in cinematic representations as being both problematic and criminalised. In doing so, this dissertation has gone some way to show how those representations and narratives that were evident in films were similar to those that existed in wider society and also in recent history. In seeking to consider the extent to which cinematic representations construct the 'junkie' as a criminalised 'Other' and the extent to which they confer legitimacy on wider socio-political understandings that see heroin and junkies as being indeterminably linked with crime and deviancy, the narrative analysis of the five films presented here also sought to respond to an identified gap in the existing scholarly body of evidence. From the analysis undertaken, the cinematic representations considered would indeed appear to go some way towards constructing junkies as criminalised outsiders that are also undoubtedly deviant. This was evident in all of the films considered. This was conveyed and given meaning through themes that sought to accentuate junkies not only being explicitly represented criminals but so too as part of a dangerous underclass, as embodying decay and depravity, and female junkies as 'whores'. Cinematic representations therefore do indeed coincide with wider socio-political views and understandings; intrinsically linked to criminality and deviancy while also being characterised by that which goes against societal notions of the normal and normative.

The analysis of Sid and Nancy, Requiem for a Dream, The Basketball Diaries, Trainspotting and T2 all gave a lens through which to view the junkie. Sid and Nancy, provided us with a lens through which to view the representation of female junkies and how they are depicted as being sexually promiscuous and deviant. In Requiem for a Dream, a lens was afforded that reinforced this view through the inclusion of another female character which descended into depravity at the behest of heroin usage. The films were helpful in providing narratives, by which themes could be identified around what it means to be a heroin user, how the image of the user is represented, and how those representations concur with stereotypical depictions highlighted in the wider literature in particular the embodiment of 'Otherness' and decay (Taylor, 2008). Such was given further credence by the lens afforded by Trainspotting and $T 2$ and their respective representations of junkies as part of a dangerous underclass. In sum, the films reaffirmed the wider scholarly view that both heroin and its users - the much-maligned junkie - are wholly demonised. In doing so, films continue to reinforce narratives about junkies being 'dirty dope-fiends', criminalised and deviant that need a strong response and punitive punishments from the state and its institutions. In conclusion, this article contributes new knowledge that responding to an identified and significant gap in the existing scholarly canon. While further research and analysis is required, this article provides a foundation upon which further investigation and analysis can be based.

Funding: This research received no external funding.

Conflicts of Interest: The authors declare no conflict of interest.

\section{References}


707

708

709

710

711

712

713

714

715

716

717

718

719

720

721

722

723

724

725

726

727

728

729

730

731

732

733

734

735

736

737

738

739

740

741

(Appel 2008) Appel, M 2008. Fictional Narratives Cultivate Just-World Beliefs. Journal of Communication. 58 (1): 62-83.

(Becker 1963) Becker, H.S 1963. Outsiders: Studies in the Sociology of Deviance. New York: The Free Press.

(Bell 1996) Bell, D 1996. The Cultural Contradictions of Capitalism. New York: Basic Books.

(Berridge 1999) Berridge, V 1999. Opium and the People: Opiate Use and Drug Control Policy in Nineteenth Century England. London. Free Association Books.

(Boyd 2008) Boyd, S.C 2008. Hooked: Drug War Films in Britain, Canada and the United States. Toronto. Routledge.

(Burroughs 1977) Burroughs, W 1977. Junky, London: Penguin.

(Carnwarth 2002) Carnwath T and Smith L, 2002. Heroin century. London: Routledge.

(Courtwright 2001) Courtwright D. T 2001. Dark Paradise: A history of opiate addiction in America. Cambridge Harvard University Press.

(Ferrell 1999) Ferrell, J 1999. Cultural Criminology. Annual Review of Sociology. 25 (1): 395-418.

(Fitzgerald 2002) Fitzgerald, J 2002. Drug Photography and Harm Reduction; Reading John Ranard, International Journal of Drug Policy, 13: (5): 369-385.

(Graber \& Dunaway 2017) Graber, G. A. \& Dunaway, J. 2017. Mass Media and American Politics. Chicago. CQ Press.

(Hall 1997) Hall, S 1997. Representation: Cultural Representations and Signifying Practices. London. Sage Publications.

(Hickman 2002) Hickman, T 2002. Heroin Chic: The Visual Culture of Narcotics Addiction. Third Text. 16(2): 119136.

(Hjelm 2014) Hjelm, T 2014. Social Constructionism's: Approaches to the study of the human world. London: Palgrave Macmillan.

(Huggins 2006) Huggins, R 2006. The Addicts Body: Embodiment, drug use and representation. Burlington: Ashgate Publications.

(Lee 2015) Lee, L 2015. Drugs in the Media: The Production of hegemony; Sociological Imagination: 4 (1): 1-10.

(Levine 1978) Levine, H 1978. The Discovery of Addiction: Changing perceptions of Habitual Drunkenness in America: Journal of Studies on Alcohol: 39 (1): 143-174.

(Loukides \& Fuller 1996) Loukides P \& Fuller L.K, 1996. Beyond the Stars: Themes and ideologies in American popular film: Bowling Green: Popular Press.

(Lovoie 2011) Lovoie, D 2011. Smoking the other: Marijuana and counterhegemony in weeds. Substance use and Misuse, 46 (7): 910-921.

(Markert 2013) Markert, J. 2013. Hooked in film. Substance abuse on the big Screen. Toronto: Scarecrow Press.

(May 2002) May, T 2002. Qualitative Research in Action. London. Sage Publications.

(McKenna 2012) McKenna, S. A 2012. The Meth Factor: Stigma, Authoritative discourse, and women who use: Colorado: Researchgate. 
(Miles \& Huberman 1994) Miles, M.B \& Huberman, A. M 1994. Qualitative Data Analysis. London. Sage Publications.

(Murray 1984) Murray, C. 1984. Losing ground. New York. Harper Collins.

(Pehlke et al 2009) Pehlke,T., Allen,,II, Hennon, C. B., Radina, M. E., \& Kuvalanka, K. A. 2009. Does father still know best? An inductive thematic analysis of popular TV sitcoms. Fathering, 7(2): 114-139.

(Polkinghorne 2006) Polkinghorne, D. E. 2006. Narrative configuration in qualitative analysis. International Journal of qualitative studies in education. 8 (1): 5-23.

(Radcliffe \& Stevens 2008) Radcliffe, P. C. and Stevens, A 2008. Are drug treatment services only for 'thieving junkie scumbags'? Drug users and the management of stigmatised identities. Social Science and Medicine, 67 (7): 1065-1073.

(Reinarman \& Duskin 1999) Reinarman, C. Duskin, C. 1999. Dominant Ideology and Drugs in the Media. In Ferrell, J and Websdale N. Making Trouble, Cultural Constructions of Crime deviance and control. (pp.73-87). New York. Adeline De Gruyter.

(Reinarman \& Levine 1997) Reinarman, C., and Levine, H. G. (1997). Crack in America: Demon drugs and social justice Berkeley: University of California Press.

(Rinke 2016) Rinke, A. 2016. Junkie love: Romance and addiction on the big screen. Cogent Arts and Humanities, 3 (1): $1-10$.

(Rock 1973) Rock, P. 1973. Deviant Behaviour. London: Hutchinson \& Co Publishers.

(Shapiro 2003) Shapiro, H 2003. Shooting Stars, Drugs, Hollywood and the Movies. Boston. Serpents Tale Publications.

(Springer \& Page 2013) Springer, M. \& Page, J B 2013. The Social Value of Drug Addicts: Uses of the Useless: London. Taylor and Francis.

(Stevenson 2000) Stevenson, J. 2000. Addicted: The myth and menace of drugs in film. London: Creation.

(Sulkumen \& Warpenius 2000) Sulkunen, P, \& Warpenius, K 2000. Reforming the self and the other: the temperance movement and the duality of modern subjectivity. Critical Public Health, 10: (4): 423-438.

(Surette 2007) Surette, R. (2007). Media, Crime, and Criminal Justice: Images, Realities, and Policies. Belmont, Thomson Wadsworth.

(Taylor 2008) Taylor, S 2008. Outside the Outsiders: Media Representations of drug use: The Journal of Community and Criminal Justice, 55, (4): 369-387.

(Turner 2003) Turner, B 2003. Social Fluids: Metaphors and Meanings, Body and Society, 9, (1): 1-10.

(Welsh, Fleming \& Dowler 2010) Welsh, A., Fleming, T \& Dowler, K., 2010. Constructing crime and justice on film: meaning and message in cinema. Contemporary Justice Review Issues in Criminal, Social, and Restorative Justice. 14 (4): 457-476. 